\title{
A ETERNA BUSCA DO INDIVISÍVEL: DO ÁTOMO FILOSÓFICO AOS QUARKS E LÉPTONS
}

Francisco Caruso

Centro Brasileiro de Pesquisas Físicas - Rua Dr. Xavier Sigaud, 150 - 22290-180 - Rio de Janeiro - RJ

Vitor Oguri

Instituto de Física da Universidade do Estado do Rio de Janeiro - Rua São Francisco Xavier, 524 - 20550-013 - Rio de Janeiro - RJ

Recebido em 30/5/96; aceito em 7/11/96

THE ETERNAL SEARCH FOR THE INDIVISIBLE: FROM PHILOSOPHICAL ATOM TO QUARKS AND LEPTONS. The fascinating search of the inner boundaries of the Universe, has been entangled, since the birth of greek philosophy 25 centuries ago, with the main epistemological changes in the History of Science. This paper does not intend to present a systematic description of the discovery of the elementary particles. By stressing the main achievements of the knowledge of matter's structure and their dependence on symmetry arguments, it is argued that even considering profound differences in each historical period, there is a paradgima of atom shared by Chemistry and Particle Physics. This text could help High School Teachers of Chemistry and Physics, as well as motivate them, in the challenge of explaining to their pupils how the idea of atom evolved.

Keywords: elementary particles; atoms; quarks; leptons.

In method [science] is an interaction of induction and deduction, while in purpose it is an interplay of the comprehension and conquest of nature.

- S. Sambursky ${ }^{1}$

\section{INTRODUÇÃO E MOTIVAÇÃO}

Nosso interesse pela Física de Partículas teve como base dois tópicos que integram o currículo dos Cursos de Química Geral do $2^{\circ}$ Grau: o estudo das regularidades das propriedades físico-químicas dos elementos naturais, que levaram à construção da Tabela Periódica de Mendeleiev, e o estudo dos modelos atômicos da Física Moderna. Apesar do seu caráter estático, da taxonomia dos elementos, sintetizada na Tabela de Mendeleiev, emerge um aspecto positivo e de grande relevância para o desenvolvimento da Ciência Moderna, i.e., a revelação da importância das simetrias, e de seu poder preditivo.

A beleza da experiência e das hipóteses de Rutherford, bem como do modelo atômico de Bohr, por outro lado, apontam em uma direção complementar, mas igualmente importante, que é o papel dinâmico das simetrias, marcante no desenvolvimento da Mecânica Quântica e da Física de Partículas.

Lançar mão de argumentos de simetria está intimamente relacionado ao não-saber (socrático), tão presente no processo da pesquisa científica mas, infelizmente, tão afastado do quotidiano das salas de aula. Deve-se, portanto, procurar explicitar o importante papel do estudo das simetrias na tentativa de compreensão da Natureza. Sugere-se que a história do conceito de átomo se presta muito bem a este propósito e deve ser explorada neste sentido.

Este artigo inclui algumas reflexões sobre o método científico e seu impacto na evolução da compreensão da constituição da matéria, ressaltando a diferença entre o átomo filosófico, produto do pensamento grego clássico, e o átomo científico, que teve origem na Química Moderna. Da eletrólise de

E-mail: CARUSO@LAFEX.CBPF.BR

E-mail: OGURI@VAX.FIS.UERJ.BR
Faraday à descoberta do nêutron, na década de 30, faz-se um esboço das contribuições da Física à conclusão de que o átomo não é indivisível. A seguir, aborda-se o período que vai do início da década de 30 à década de 60, quando foi possível estabelecer uma nova classificação estática das partículas elementares então conhecidas. Assim como o sucesso da Tabela Periódica da Química subentende o conceito de átomo, esta nova classificação das partículas elementares pressupõe o conceito de novas partículas indivisíveis - os quarks. Por último, discutem-se as conquistas da Física de Partículas, do final da década de 60 até os dias de hoje, e mostra-se como estas novas partículas — os quarks — são descritas através de uma nova teoria dinâmica e são, de certa forma, os tijolos fundamentais da matéria. Desta maneira é possível concluir que o fato de a Física Moderna estar constantemente dividindo o indivisível $^{2}$ não implica, ou pelo menos não implicou até o presente, o abandono do paradigma de átomo, embora possa modificá-lo.

Mesmo se compreendermos que o significa-
do de um conceito jamais será definido com
precisão absoluta, alguns conceitos são par-
te integrante dos métodos da ciência, pelo
fato de representarem, pelo menos por al-
gum tempo, o resultado final do desenvolvi-
mento do pensamento humano desde um
passado assaz remoto; eles podem mesmo ter
sido herdados e são, qualquer que seja o
caso, instrumentos indispensáveis na execu-
ção do trabalho científico em nosso tempo.
- W. Heisenberg

\section{UM BREVE COMENTÁRIO SOBRE A ORIGEM DA FÍSICA GREGA}

A primeira fase da filosofia grega corresponde ao período entre os séculos VI e IV a.C. e teve suas origens na chamada Escola de Mileto. Quando hoje se considera que Tales de Mileto responde à pergunta "De que é constituída a matéria?", afirmando ser "a água a causa material de todas as coisas", pode parecer-nos absurdo. No entanto, esta resposta representa uma drástica mudança de atitude com relação à Natureza 
(Physis), de grande importância para a evolução deste tipo de filosofia, refletindo-se, de certa forma, no procedimento científico contemporâneo. Ela pressupõe inicialmente a idéia de causa: a matéria tem uma causa, e a explicação causal da Natureza deve ainda ser racional (em contraposição aos mitos). O entendimento da Natureza está ligado, segundo Tales, a um único princípio: a água. Este ideal de simplicidade na descrição dos fenômenos físicos é compartilhado, mutatis mutandis, por pensadores como Aristóteles, William de Ockham, Maupertuis, Einstein e Dirac, entre outros.

Estas questões primeiras foram amplamente discutidas pelos Pré-Socráticos - dentre eles os atomistas Leucipo e Demócrito - por Platão e por Aristóteles. Apesar das marcantes diferenças de opinião, este período caracteriza-se, em linhas gerais, pelo ideal de Cosmos (Mundo em latim), que significa "ordem", e pela convicção de que a ordenação da variedade infinita das coisas e eventos possa (e deva) ser alcançada racionalmente. Portanto, para os Gregos, a compreensão da Natureza passa necessariamente pela busca de um tipo de ordem o que, por sua vez, requer o reconhecimento do que é igual, do que é regular, a capacidade de reconhecer simetrias: tudo em busca de uma Unidade. Para Tales esta unidade era a água, para Heráclito era o fogo, enquanto eram o átomo (o cheio) e o vazio a representá-la para os Atomistas. A relevância desses pontos para a Física pós-galileana ficará evidente mais adiante.

Now of the two triangles, the isosceles has one form only; th scalene (...) has an infinite number. Of the infinite forms we must again select the most beautiful, if we are to proceed in due order, and anyone who can point out a more beautiful form than ours for the construction of these bodies, shall carry off the palm, not as an enemy, but as friend.

Platão ${ }^{4}$

\section{3. ÁTOMOS, VAZIO E TRIÂNGULOS}

O conceito de átomo foi introduzido na Filosofia por Leucipo e elaborado em seus detalhes por Demócrito ${ }^{5,6}$. Eles aceitaram a existência do vazio e postularam a existência de inúmeros elementos em movimento perpétuo: os átomos. Espaço e matéria se excluem reciprocamente e formam a base da grande escola materialista da antigüidade, que, curiosamente, atribuía uma realidade a algo que não fosse corpo (ao vazio, ao não-Ser). Átomos e vazio, juntos, são as causas das coisas existentes e as três diferenças dos átomos, i.e., forma, disposição e posição, explicam a diversidade delas.

É claro que, ao contrário dos elementos primordiais água, terra, ar e fogo, escolhidos por outros filósofos como essência de suas filosofias, o átomo não pode ser visto ou tocado e não tem propriedades da matéria, como, por exemplo: cor, gosto, cheiro etc. Estas últimas aparecem como resultado das posições e movimentos relativos dos próprios átomos. Portanto, de alguma forma, tais propriedades dependem do vazio que serve como sustentáculo para o movimento dos átomos resultante de colisões mútuas.

Será visto mais adiante que o programa atomista só alcançará um status científico com a Química, no início do séc. XIX. Antes, porém, é pertinente comentar, ainda que brevemente, outra visão antiga da essência das coisas, i.e., a de Platão, importantíssima na História da Ciência.

Essencialmente, pode-se dizer que o programa filosófico de Platão, no que tange a descrição da natureza, pressupõe uma espacialização da matéria e uma geometrização da física. Sob a influência de Empédocles e dos Pitagóricos, Platão afirma, no Timeo, que a menor parte de cada um dos quatro elementos da filosofia de Empédocles relaciona-se com os poliédros regulares da Geometria, descobertos pelos Pitagóricos. O fato que se quer chamar a atenção é que as entidades fundamentais não se confundem com a menor parte da matéria, pois estas correspondem aos sólidos regulares, e estes são ainda formados por triângulos equiláteros e isósceles, que podem se recombinar dando origem a outros sólidos. As entidades fundamentais da filosofia de Platão são, portanto, formas matemáticas e não tijolos indivisíveis como os átomos. A valorização da simetria - implícita no ideal platônico de geometrizar a Natureza - permitirá, por exemplo, que se postulem novos constituintes da matéria nuclear, os quarks, como entidades matemáticas nos trabalhos de Gell-Mann e Zweig ${ }^{7}$ da década de 60, como será mostrado mais adiante.

Qualquer que seja o ponto de partida de atividade científica, esta atividade não pode convencer plenamente senão deixando o domínio de base: se ele experimenta é preciso raciocinar; se ela raciocina é preciso experimentar.

G. Bachelard ${ }^{8}$

\section{UM BREVE COMENTÁRIO SOBRE O MÉTODO DA FÍSICA MODERNA}

Durante a Idade Média, o Homem passa a ser o centro dos interesses e de suas próprias preocupações, e o atomismo, enquanto doutrina filosófica, é praticamente abandonado. O olhar do Homem volta-se para questões humanísticas e espirituais, para Deus. É a partir de Copérnico, em 1543, que o Homem deixa de estar no centro do Mundo, quando o sistema geocêntrico é substituído pelo sistema heliocêntrico. Há, neste momento, uma ruptura da ordem aristotélica. Enquanto a física do mundo sub-lunar continua sendo essencialmente descrita pelas idéias de Aristóteles, os céus não. Esta crise da Ciência só será resolvida por Newton.

Com o início da Renascença Italiana surge um crescente interesse com relação à Natureza. Foi mais exatamente nos Sécs. XVI e XVII que a Ciência Natural tomou grande impulso. Sabese que a origem do método científico contemporâneo é atribuída a Galileu, porquanto ele combina, de forma indissolúvel, o conhecimento empírico com a Matemática. Em suas palavras:

"La filosofia è scritta in questo grandissimo libro che continuamente ci sta aperto innanzi a gli occhi (io dico l'universo), ma non si può intendere se prima non s'impara a intender la lingua, a conoscer $i$ caratteri, ne' quali è scritto. Egli è scritto in lingua matematica, e $i$ caratteri son triangoli, cerchi, ed altre figure geometriche, senza i quali mezi è impossibile a intenderne umanamente parola; senza questi è un aggirarsi vanamente per un oscuro laberinto."9

Ampliam-se, assim, os ideais copernicanos de geometrização, até então restritos à Astronomia. Além disto, os modelos matemáticos devem ser testados através da experimentação. Houve, portanto, com Galileu uma mudança epistemológica radical na Física.

Já para Newton, o elemento básico da Física é a lei do movimento e não a essência da matéria, ou as formas geométricas, como na filosofia grega. Em seus Principia Mathematica ele se preocupa com a descrição causal do movimento dos corpos e formas em um espaço absoluto, aceitando a visão atomista da matéria - visão esta que Newton vai extender à luz em seu livro Opticks - , como ilustra o seguinte trecho:

"All these things being consider'd, it seems probable to me that God in the beginning form'd Matter in solid, massy, hard, impenetrable, moveable Particles, of such Sizes and Figures, and with such other properties, and in such Proportion of Space, as most conduced to the End for which he formed them; and that these primitive Particles being Solids, are incomparably harder than any porous bodies compounded of them; even 
so very hard, as never to wear or break in pieces; no ordinary Power being able to divide what God himself made one in the first creation." 10 .

Essas partículas materiais, segundo Newton, interagem através de ação a distância, i.e., interagem ainda que não estejam em contacto, o que corresponde a uma relação instantânea de causa e efeito. Um exemplo disto é a lei de Gravitação de Newton. Nos cursos de Física II aprende-se uma formulação equivalente em termos do potencial e do campo gravitacional. Este segundo ponto de vista (desconhecido à época de Newton) considera que uma partícula seja capaz de modificar de algum modo as propriedades do espaço em seu redor, criando um campo gravitacional. Outra partícula colocada nessa região sentiria a presença deste campo, resultando uma força sobre ela. O campo então pode ser visto como um intermediário da interação (gravitacional neste caso) entre as partículas.

$\mathrm{Na}$ realidade, foram a síntese e o sucesso da teoria eletromagnética de Maxwell que atribuíram aos campos eletromagnéticos um significado físico tão real quanto possuem as partículas na Física Newtoniana.

Em Física Quântica, o conceito de campo vai desempenhar um papel fundamental na descrição da luz e das partículas elementares. A crise da Ciência que marca o início do Séc. XX teve início com a explicação, dada por Planck, da regularidade e da universalidade da lei de emissão de radiação dos corpos negros, a partir da idéia de quantum de ação ${ }^{11}$. Em outras palavras, Planck introduz uma nova constante fundamental $\hbar$ (cuja dimensão é a mesma do momento angular), conhecida como constante de Planck, que é o coeficiente de proporcionalidade entre a menor quantidade de energia emitida ou absorvida por um corpo negro e a freqüência da radiação. $\mathrm{O}$ real impacto desta idéia revolucionária de Planck ainda estava por ser compreendido.

Com base nessa hipótese de quantização de Planck, Einstein elaborou uma teoria para explicar o efeito fotoelétrico, introduzindo o conceito de fóton na Física ${ }^{12}$ e, mais tarde, com a descoberta do efeito Compton ${ }^{13}$, acumulam-se evidências a favor do caráter corpuscular da luz. Entretanto, outros experimentos, como a difração da luz, por exemplo, são explicados a partir da visão ondulatória da luz. Passou-se a dizer, então, que existe uma dualidade onda-partícula no que concerne à luz. Este termo dualidade esconde, na verdade, o início de uma profunda crise epistemológica da Ciência, capaz de abalar os alicerces do determinismo mecanicista a nível do microcosmo, cuja solução dependeu, crucialmente, de dois fatos: a compreensão, por parte de Niels Bohr ${ }^{14}$, de que a constante $\hbar$ seria fundamental para assegurar a estabilidade do átomo e da matéria, e a posterior generalização da crise, proposta por Louis de Broglie.

De fato, de Broglie em sua tese de Doutorado postula a existência de uma onda associada a cada partícula livre (e ondas são descritas por campos) ${ }^{15}$ ou, em outras palavras, a dualidade onda-partícula deveria aplicar-se também à matéria e não apenas à luz. É neste sentido que ele generaliza a crise a qual se aludiu acima.

Mas como modificar as idéias de de Broglie para descrever a dinâmica do microcosmo? Em particular, como aplicá-las a partículas submetidas à ação de campos, como no caso dos "elétrons atômicos"? A solução a estas questões será dada, em 1926, por Schrödinger ${ }^{16}$, ao postular que esta onda proposta por de Broglie é solução de uma equação diferencial (equação de onda) fundamental, que hoje leva o seu nome ${ }^{17}$ :

$-\frac{\hbar^{2}}{2 m} \nabla^{2} \psi(\vec{x}, t)+V(\vec{x}, t) \psi(\vec{x}, t)=i \hbar \frac{\partial \psi(\vec{x}, t)}{\partial t}$

onde $\psi(\vec{x}, t)$ denota a amplitude da onda, $V(\vec{x}, t)$ é a energia potencial da partícula, $m$ a massa, $\vec{x}$ o vetor posição, $t$ o instante de tempo e $\nabla_{2}=\frac{\partial^{2}}{\partial x^{2}}+\frac{\partial^{2}}{\partial y^{2}}+\frac{\partial^{2}}{\partial z^{2}}$ é o chamado operador diferencial laplaciano.

Esta equação, que abriu um novo capítulo na Física Moderna, é usualmente escrita em uma forma mais compacta como:

$H \psi(\vec{x}, t)=i \hbar \frac{\partial \psi(\vec{x}, t)}{\partial t}$

onde $H$ é o operador que corresponde à hamiltoniana do sistema que, no caso de sistemas conservativos $(V=V(\vec{x}, t))$, corresponde à energia total deste sistema. O leitor interessado numa abordagem didática (a nível universitário) da estrutura quântica da matéria pode consultar o livro-texto de José Leite Lopes $^{18}$ e o livro de divulgação de Armando Gibert ${ }^{19}$.

"But can nature have blanck spaces?"

Berlikov $^{20}$

\section{O ÁTOMO CIENTÍFICO: DA QUíMICA À FÍSICA}

O modelo atômico de Dalton pode ser considerado o primeiro modelo científico. Embora alguns elementos químicos considerados por Dalton (vide tabela 1) sejam, na verdade, compostos, seu modelo é compatível com leis empíricas conhecidas na época, como as de Lavoisier e de Proust. A lei de Proust diz essencialmente que em uma reação química, seja ela qual for, as massas dos elementos envolvidos guardam entre si uma relação fixa. Claro está que esta lei não determina por si só a razão entre as massas dos átomos que formam os compostos, a menos

Tabela 1. Símbolos de Dalton para os elementos químicos. Sabe-se hoje que alguns deles são compostos e não elementos. O original encontra-se no Science Museum de Londres, negativo no. 4291, Apud Gibert, op. cit.

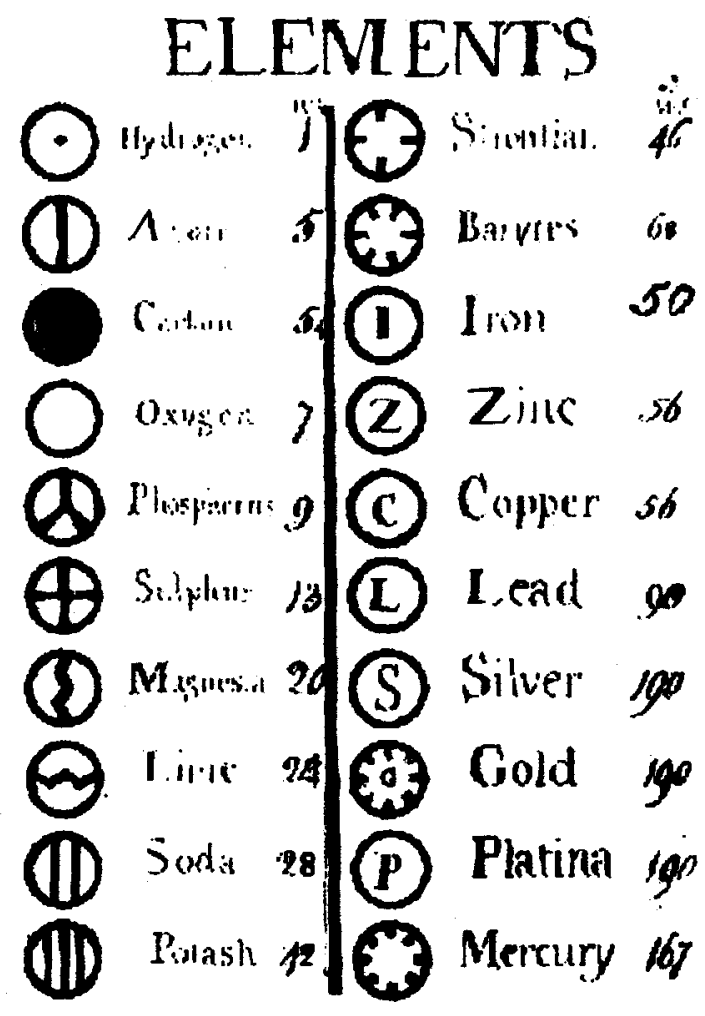


que se conheça a relação entre os números de átomos do composto. Esta lei vale para todos os compostos químicos, quaisquer que sejam seus estados físicos ${ }^{21}$. Em particular, se os reagentes estão no estado gasoso, existe uma razão simples entre os volumes dos gases. Este fato não pode ser explicado pelo modelo de Dalton, o que levou Avogadro a introduzir o conceito de molécula e admitir, por hipótese, que dois volumes iguais de dois gases quaisquer contêm o mesmo número de moléculas, desde que a temperatura e a pressão sejam as mesmas; é o conhecido número de Avogadro.

Antecipando-se ao conceito de estrutura eletrônica dos átomos, Mendeleiev conseguiu classificar os elementos químicos segundo a ordem crescente de suas massas atômicas, colocando aqueles de propriedades semelhantes em colunas, uns debaixo dos outros, na famosa Tabela Periódica, cf. Tabela 2. Em 1870, ele escreve:

"It is necessary to do one thing or the other - either to consider the periodic law as completely true, and as forming a new instrument in chemical research, or to refute it.",22

O que é relevante para o nosso escopo é ressaltar que, por ocasião da publicação de sua primeira classificação, eram conhecidos 63 elementos (as "partículas elementares"da época) e, em 1908, este número já passara a 86. Tanto a existência como as propriedades destes novos elementos foram antecipadas por Mendeleiev como conseqüência das regularidades e simetrias por ele descobertas.
A busca e a descoberta de simetrias tem sido essencial em vários outros ramos da Ciência, principalmente quando, devido ao grau de complexidade do sistema, não se podem fazer cálculos exatos ou quando não existir sequer uma teoria dinâmica capaz de tratar um sistema ou um determinado processo.

$\mathrm{O}$ acordo com a experiência de vários resultados da teoria cinética dos gases, desenvolvida por Boltzmann — que se baseia na teoria molecular da matéria - juntamente com o conceito de átomo científico elaborado pelos químicos do Séc. XIX $^{23}$ fez com que muitos outros cientistas aceitassem a visão atomista do Mundo. No entanto, sobre isto não existia consenso. Mach e Ostwald, por exemplo, acreditavam poder reduzir tudo à energia. Um trabalho que muito contribuiu para o prevalecimento do atomismo foi o estudo do movimento browniano feito por Einstein ${ }^{24}$.

Por volta da metade do século passado, acreditava-se que o movimento aleatório de partículas ínfimas de pólen em suspensão fosse devido ao fato destas serem formadas de matéria viva. Mais tarde, constatou-se que o movimento browniano é conseqüência da agitação térmica das moléculas de um fluido, a qual induz sobre os corpúsculos visíveis ao microscópio - que nele se encontram em suspensão — um movimento desordenado e aleatório. Das investigações de Einstein sobre este efeito foi possível calcular o número de Avogadro $(N)$ e o resultado é impressionante: a previsão é de $N=6,56 \times 10^{23}$ moléculas/mol a ser comparado com o valor atual $N=6,02252$ $\times 10^{23}$ moléculas $/ \mathrm{mol}$.

Tabela 2. Tabela dos Elementos de Mendeleiev de 1871. Cada número refere-se ao peso de um átomo do elemento em relação ao átomo de hidrogênio. Extraída do livro de Posin, op. cit.

\begin{tabular}{|c|c|c|c|c|c|c|c|}
\hline $\begin{array}{c}\text { Group I } \\
\text { Two atoms } \\
\text { of any element } \\
(\mathrm{R}) \text { here } \\
\text { combine with } \\
\text { one atom of } \\
\text { oxygen }(\mathrm{O}) \\
\mathrm{R}_{2} \mathrm{O}\end{array}$ & $\begin{array}{c}\text { Group II } \\
\text { One atom } \\
\text { of any element } \\
(\mathrm{R}) \text { here } \\
\text { combines with } \\
\text { one atom of } \\
\text { oxygen }(\mathrm{O}) \\
\mathrm{RO} \text { or } \mathrm{R}_{2} \mathrm{O}_{2}\end{array}$ & $\begin{array}{c}\text { Group III } \\
\text { Two atoms } \\
\text { of any element } \\
\text { (R) combine } \\
\text { with three } \\
\text { atoms of } \\
\text { oxygen }(\mathrm{O}) \\
\mathrm{R}_{2} \mathrm{O}_{3}\end{array}$ & $\begin{array}{c}\text { Gruop IV } \\
\text { One atom } \\
\text { of any element } \\
\text { (R) here } \\
\text { combines with } \\
\text { two atoms of } \\
\text { oxygen } \\
\mathrm{RO}_{2}\end{array}$ & $\begin{array}{c}\text { Group V } \\
\text { Two atoms } \\
\text { of any element } \\
\text { (R) here } \\
\text { combine with } \\
\text { five atoms of } \\
\text { oxygen }(\mathrm{O}) \\
\mathrm{R}_{2} \mathrm{O}_{5}\end{array}$ & $\begin{array}{c}\text { GroupVI } \\
\text { One atom } \\
\text { of any element } \\
(\mathrm{R}) \text { here } \\
\text { combines with } \\
\text { three atoms of } \\
\text { oxygen }(\mathrm{O}) \\
\mathrm{RO}_{3}\end{array}$ & $\begin{array}{l}\text { Group VII } \\
\text { Two atoms } \\
\text { of any element } \\
\text { (R) here } \\
\text { combine with } \\
\text { seven atoms of } \\
\text { oxygen }(\mathrm{O}) \\
\mathrm{R}_{2} \mathrm{O}_{7}\end{array}$ & $\begin{array}{l}\text { Group VIII } \\
\text { One atom } \\
\text { of any element } \\
\text { (R) here } \\
\text { combines with } \\
\text { four atoms of } \\
\text { oxygen }(\mathrm{O}) \\
\mathrm{RO}_{4}\end{array}$ \\
\hline \multicolumn{8}{|l|}{ Hydrogen $=1$} \\
\hline Lithium $=7$ & Beryllium $=9.4$ & Boron $=11$ & Carbos $=12$ & Nitrogen $=14$ & Oxygen $=16$ & Fluorine $=19$ & \\
\hline Sodium $=23$ & Magnesium $=24$ & Aluminium $=27.3$ & Silicon $=28$ & Phosphorus $=31$ & Sulphur $=32$ & Chlorine $=35.5$ & \\
\hline Potassium = 39 & Calcium $=40$ & $--=44$ & Titanium $=48$ & Vanadium $=51$ & Chromium $=52$ & Manganese $=55$ & $\begin{array}{l}\text { Iron }=56 \\
\text { Cobalt }=59 \\
\text { Nickel }=59 \\
\text { Copper }=63\end{array}$ \\
\hline Copper $=63$ & Zinc $=65$ & $--=68$ & $-=72$ & Arsenic $=75$ & Selenium $=78$ & Bromine $=80$ & \\
\hline Rubidium $=85$ & Strontium $=87$ & $? \mathrm{y}=88$ & Zirconium $=90$ & $--=94$ & Molybdenum $=96$ & $--=100$ & $\begin{array}{l}\text { Ruthenium = } 194 \\
\text { Rhodium = } 104 \\
\text { Lead = } 106 \\
\text { Silver = } 108\end{array}$ \\
\hline Silver $=108$ & Cadmium $=112$ & Indium $=113$ & $\operatorname{Tin}=118$ & Antimony $=122$ & Tellurium $=125$ & Iodine $=127$ & \\
\hline Cesium $=133$ & Barium $=137$ & $? \mathrm{Di}=138$ & $? \mathrm{Ce}=140$ & $\ldots \ldots$ & $\ldots \ldots$ & ...... & $\ldots \ldots$ \\
\hline$\ldots \ldots$ & $\ldots \ldots$ & $\ldots \ldots$ & ...... & $\ldots \ldots$ & $\ldots \ldots$ & ....... & $\ldots \ldots$ \\
\hline ....... & $\ldots \ldots$ & $? \mathrm{Er}=178$ & $? \mathrm{La}=180$ & Tantalum $=182$ & Tungsten $=184$ & $\ldots \ldots$ & $\begin{array}{l}\text { Osmium = } 195 \\
\text { Iridium = } 198 \\
\text { Platinum = } 97 \\
\text { Gold = } 197\end{array}$ \\
\hline Gold $=197$ & Mercury $=200$ & Thallium $=204$ & Lead $=207$ & Bismuth $=208$ & $\ldots .$. & $\ldots . .$. & \\
\hline$\ldots$ & $\ldots \ldots$ & $\ldots \ldots$ & Thorium $=231$ & ...... & Uranium $=240$ & $\ldots \ldots$ & $\ldots \ldots$ \\
\hline
\end{tabular}


Tudo que foi dito até aqui parece confirmar o caráter indivisível do átomo, salvo, talvez, a existência de isótopos e isóbaros. Mas são os átomos realmente indivisíveis? Existe alguma experiência que possa verificar esta hipótese? A resposta é $\operatorname{sim}^{25}$.

A primeira coisa que se pode indagar é como se explica o fenômeno de eletrificação de certos materiais por atrito se os átomos são eletricamente neutros. A eletrólise de Faraday foi uma primeira evidênca quantitativa a favor de constituintes carregados no interior da matéria (os chamados "átomos de eletricidade", batizados de elétrons (e), em 1894), bem como da natureza discreta da carga elétrica. No entanto, somente a partir de 1857, com o aperfeiçoamento das técnicas de trabalhos com vidros e das máquinas de fazer vácuo desenvolvidas por Geissler, é que foi possível a construção do que se poderia chamar de o primeiro acelerador de partículas: o tubo de raios catódicos. Se for posto aí o marco da era dos aceleradores, fica evidente que ela já tem início com uma íntima relação entre ciência pura e tecnologia; relação esta que vem se estreitando cada vez mais, tornando-se indispensável ao desenvolvimento da Física de Partículas e de tecnologias associadas.

Desde a metade do século passado, físicos como Crookes e J. J. Thomson dedicaram-se à tentativa de entender e explicar a natureza do facho que aparece dentro desses tubos ${ }^{26,27}$. Através de uma série de experimentos, chegou-se à conclusão de que o feixe luminoso era constituído de partículas carregadas. Em 1897, Thomson conseguiu medir, com boa precisão, a razão entre a carga e a massa destas partículas, encontrando um valor muito maior que para íons em eletrólises, indicando que a ordem de grandeza da massa dessas partículas era muito pequena $^{28}$. Ainda neste mesmo artigo, ele verificou que estes corpúsculos carregados eram exatamente os mesmos, quaisquer que fossem os elementos do catodo, do anodo e do gás dentro do tubo. Estes pareciam ser constituintes universais da matéria (os elétrons), mostrando empiricamente que o átomo não é indivisivel. Dois anos mais tarde, Thomson pode estimar que a massa dos elétrons $\left(m_{\mathrm{e}}\right)$ era 1840 vezes menor que a do íon de hidrogênio $\left(m_{\mathrm{p}}\right)$, o próton, termo introduzido na Física somente em 1919.

A carga do elétron foi medida, em 1909, por Millikan ${ }^{29}$, com boa precisão, e seu caráter discreto foi confirmado. A carga elétrica é uma constante fundamental da natureza e todos os elétrons têm a mesma carga. Os átomos como um todo são neutros; o que significa que a carga do núcleo (descoberto por Rutherford) deve ser positiva e neutralizar a carga dos elétrons das camadas eletrônicas. No caso do hidrogênio, o núcleo é simplesmente o próton. Apesar de prótons e elétrons terem muitas propriedades fundamentalmente diferentes, a explicação do porquê eles têm cargas elétricas com exatamente o mesmo módulo é ainda um grande desafio para a Física. Apresenta-se agora, brevemente, como surge o conceito de núcleo atômico.

Como por volta de 1910 não se dispunha de aceleradores capazes de produzir feixes de partículas de alta energia, Rutherford fez incidir partículas alfa $(\alpha)^{30}$ sobre uma lâmina metálica delgada ${ }^{31}$. Sendo a lâmina constituída de átomos, esperava-se na época, com base no modelo de Thomson, que a deflexão dessas partículas fosse muito pequena. No entanto, o resultado foi surpreendente. Aproximadamente uma a cada dez mil partículas $\alpha$ era espalhada para trás (ângulos maiores do que $\pi / 2$ ). Medindo acuradamente a distribuição angular do espalhamento, Rutherford chegou à conclusão de que nestes casos raros o espalhamento resultava da colisão da partícula $\alpha$ com minúsculos centros espalhadores no interior do átomo, contendo praticamente toda sua massa: estava descoberto o núcleo atômico (no caso do Hidrogênio, o próton).

Além da relevância da conclusão do trabalho de Rutherford para a física atômica, cabe ainda ressaltar que seu experimento marcou época para a física experimental de altas energias. Seu princípio básico é usado até hoje (naturalmente envolvendo uma tecnologia muito mais avançada), i.e., acelerar e fazer incidir um feixe colimado de partículas sobre um alvo fixo. Uma variante desta técnica deu origem aos Colliders (Anéis Colisores), onde dois feixes de partículas de alta energia (podem ser ambos de partículas ou um de partículas e o outro de anti-partículas) são colimados para um ponto comum onde ocorrem as colisões, e ao redor desta região distribuem-se os detectores. Alguns exemplos de Colliders em funcionamento são o $\operatorname{LEP}^{32}$ do CERN ${ }^{33}$, na Suíça, o Tevatron do FERMILAB ${ }^{34}$, nos E.E.U.U. (feixes de próton e antipróton), e mais um grande projeto europeu: o $\mathrm{LHC}^{35}$, também no CERN, usando feixes de prótons.

It is of course possible to supose that the neutron may be an elementary particle. This view has little to recommend it at present, except the possibility of explaining the statistics of such nuclei as $\mathrm{N}^{14}$.

- J. Chadwick, $1932^{36}$

\section{POR QUE UM NÚCLEO DE CARGAS POSITIVAS NÃO EXPLODE?}

De volta à perspectiva histórica do artigo, pode-se afirmar que o núcleo atômico foi estudado com muito interesse na primeira metade do século, do que foi possível apreender seu caráter complexo. Como antes de 1932, ano em que foi descoberto o nêutron $(n)$, conheciam-se apenas três partículas: elétron $(e)$, próton $(p)$ e fóton $(\gamma)^{37}$, pensou-se inicialmente que o núcleo fosse constituído de prótons e elétrons. Tal modelo apresenta vários problemas, dentre os quais a previsão em desacordo com medidas do momento angular intrínsico (spin) de alguns núcleos, como será visto a seguir.

Considere-se, por exemplo, o núcleo $7^{14} \mathrm{~N}$, mencionado na citação de Chadwick. Como a massa do próton é aproximadamente 2000 vezes maior do que a do elétron e a massa atômica (A) deste núcleo é 14, dever-se-ía ter 14 prótons dentro do núcleo e, para o átomo como um todo ser eletricamente neutro, deveriam existir 7 elétrons no seu interior. Este modelo implicaria, então, um número ímpar de constituintes de spin $1 / 2$ que de forma alguma podem se combinar para dar o valor inteiro medido experimentalmente. Outro fato que este modelo não explicava era a emissão de elétrons de baixa energia por núcleos pesados.

A descoberta do nêutron em 1932, por Chadwick ${ }^{38,}$ resolve o problema do spin inteiro de certos núcleos. De fato, tendo o nêutron uma massa muito próxima àquela do próton o núcleo teria 7 prótons e 7 nêutrons e, portanto, $A=14$ e $Z=7$ e o total de partículas de spin $1 / 2$ seria par, podendo resultar num spin total inteiro.

No entanto, fica ainda a dúvida: por que a grande maioria dos núcleos não explode? Sim, pois os núcleos com $\mathrm{A} \neq 1$ teriam partículas de carga elétrica positiva concentradas em uma região espacial da ordem de $10^{-13} \mathrm{~cm}$, onde se esperaria que a repulsão coulombiana fosse significativa, pois esta força varia como $1 / r^{2}$.

Uma hipótese plausível é a existência de forças de natureza diversa da eletromagnética ou gravitacional, que atuariam somente na escala da dimensão nuclear, assegurando a estabilidade dos núcleos.

Sabe-se hoje que estas forças de fato existem e levam o nome de forças nucleares ou ainda de forças fortes. Desta nova interação depende a constituição dos núcleos atômicos e ela é realmente muito intensa. Uma estimativa muito crua nos indica que ela é da ordem de 2000 vezes maior do que a força eletromagnética, cuja intensidade é dada pela constante de estrutura fina eletromagnética, $\alpha=1 / 137$, introduzida por Sommerfeld.

$\mathrm{Na}$ verdade, a física sub-nuclear dos últimos 50 anos dividiuse em grandes linhas referentes à natureza da força responsável pelo fenômeno em questão. Assim, fala-se tradicionalmente em: 
- processos eletromagnéticos, interações entre partículas com carga elétrica, responsáveis (levando-se em conta o princípio de exclusão de Pauli) pelas estruturas atômicas, e são objetos de estudo da chamada Eletrodinâmica Quântica (QED);

- processos fracos, interações entre quaisquer partículas fundamentais, responsáveis pelos decaimentos beta $(\beta)^{39}$, assim chamados pelo pequeno valor da constante de acoplamento de Fermi, $\mathrm{G}_{\mathrm{F}}=10^{-5} \mathrm{~m}_{\mathrm{p}}^{-2}$, que caracteriza a intensidade das interações. Na verdade, como a dimensão da constante de Fermi é $\left[\mathrm{G}_{\mathrm{F}}\right]=\mathrm{L}^{2}$, estes processos deveriam ser chamados de "curtos", em vez de "fracos", mas este último é o termo mais usado.

- processos fortes, interações apenas entre quarks e gluons, responsáveis pelos fenômenos nucleares como já mencionado acima; são caracterizadas por uma constante de acoplamento $\left(\alpha_{\mathrm{s}}\right)$ numericamente maior que a constante eletromagnética $(\alpha)$ e a constante de Fermi.

Além destas três forças, existe ainda a força gravitacional que, no entanto, não é relevante para o estudo dos fenômenos sub-nucleares, na escala de energia disponível hoje para sondar a matéria. Por exemplo, a força de atração gravitacional entre dois elétrons é da ordem de $10^{40}$ vezes menor que a força de repulsão elétrica entre eles, a paridade da distância relativa que os separa.

Visando introduzir o conceito de quark, fez-se a opção de focalizar principalmente a evolução da compreensão das interações fortes de forma bem fenomenológica e descritiva, a partir de certas simetrias dos constituintes do núcleo.

Com a verificação de que a massa do próton $\left(m_{\mathrm{p}}\right)$ era praticamente igual a do nêutron $\left(m_{\mathrm{n}}\right), m_{\mathrm{p}} \cong m_{\mathrm{n}}$, e de que as interações fortes não dependem da diferença de carga elétrica entre prótons e nêutrons, Heisenberg sugeriu, em 1932, que estas duas partículas poderiam ser tratadas como diferentes estados de carga de uma única partícula: o nucleon. Ao nucleon associa-se um novo número quântico chamado isospin ${ }^{40}$, denotado por $I$, com valor $I=1 / 2$ e dois sub-estados: $I_{z}= \pm 1 / 2$. Neste modelo, a carga elétrica $(Q)$ dos dois estados do nucleon é dada (em unidades de carga do próton - $e$ ) por:

$$
\frac{Q}{e}=\frac{1}{2}+I_{z}
$$

com $I_{z}=+1 / 2$ para o próton e $I_{z}=-1 / 2$ para o nêutron.

Apesar da simetria de isospin ser aproximada, ela é útil porque $I$ é um número quântico conservado nas interações fortes, embora não se conserve nas interações fraca e eletromagnética. Deste fato decorre uma série de regras de seleção que podem ser testadas experimentalmente. Já a interação eletromagnética não conserva isospin, pois ela naturalmente distingue entre estados de cargas diferentes como o próton e o nêutron.

Assim, por volta de 1932, conheciam-se três "tijolos fundamentais da matéria": próton $(p)$, elétron (e) e nêutron (n). Uma quarta partícula, o fóton $(\gamma)$, seria a mediadora do campo eletromagnético; o quantum deste campo.

Il problema fondamentale nella fisica teorica dell'ultima ventina d'anni è costituito forse dalla ricerca di una descrizione delle particelle elementari e delle loro interazioni.

E. Fermi, $1952^{41}$

\section{QUANTOS “ÁTOMOS”?: O ZOOLÓGICO DE PARTÍCULAS}

O período que se sucedeu à descoberta do nêutron foi extraordinariamente fecundo para o estudo das partículas elementares e suas interações, pois muitas novas partículas foram descobertas e novas visões do mundo subnuclear começaram a surgir:

- O anti-elétron, chamado pósitron $\left(e^{+}\right)$, descoberto em 1932, havia sido previsto teoricamente por Dirac nos anos 1930-31;

- O neutrino ( $v$ ) foi postulado por Pauli em 1931-33, a partir do estudo teórico do decaimento $\beta$, para "salvar" as leis de conservação de energia-momentum e de momento angular;

- Usando técnicas de raios cósmicos foram descobertos o múon $(\mu)$ e o méson $\pi$ (píon);

- Daí em diante, foi descoberta uma grande quantidade de partículas que não tinham propriamente a característica de "tijolos fundamentais" pois viviam somente por tempos brevíssimos. Alguns exemplos são: $\mathrm{K}, \rho, \lambda, \Sigma, \Xi, \Delta$ etc. Ao leitor interessado numa apresentação histórica do descobrimento de várias destas partículas indicam-se as referências ${ }^{42,43,44,45}$.

A hipótese da existência de um anti-elétron, ou seja, o conceito de anti-partícula foi de importância fundamental no desenvolvimento da física de partículas. A idéia de que para cada partícula existe uma correspondente anti-partícula (com mesma massa e carga elétrica oposta) permite a previsão de um grande número de novos fenômenos e a própria modificação do conceito de vácuo, como será visto na seção 8 .

A hipótese de Pauli, associando ao elétron um férmion de massa nula (neutrino), foi estendida também a outras partículas similares ao elétron, como o múon.

Outra idéia muito importante para o desenvolvimento da Física de Partículas foi a hipótese feita por Yukawa, em 1934, de que a interação forte entre prótons e nêutrons no interior dos núcleos dar-se-ía através de um quantum hipotético: o "agente mediador da força". Sabe-se, hoje, que a partícula que tem as características deste quantum é o méson $\pi$, descoberto experimentalmente, em 1947, por um grupo do qual fazia parte o físico brasileiro C. Lattes ${ }^{46,47}$. No caso da teoria eletromagnética este quantum é o fóton. Por que o méson mediador das forças fortes teria massa e o fóton não?

$\mathrm{O}$ argumento de Yukawa baseou-se na hipótese de que o alcance de uma interação estaria relacionado à massa do mediador. Assim, em analogia com as interações eletromagnética e gravitacional de longo alcance, onde os mediadores não possuem massa, uma interação de curto alcance estaria associada a um mediador massivo. Portanto, para interações que ocorrem em regiões espaciais da ordem de $10^{-13} \mathrm{~cm}$ parece ser imperativo que o quantum do campo nuclear seja massivo $(m \approx 140 \mathrm{MeV})$. No entanto, ver-se-á mais tarde que isto não é necessário.

A base matemática do argumento de Yukawa é simples. Dada a relação de Einstein entre massa $(m)$, energia $(E)$ e momentum $(p)$ de uma partícula livre,

$E^{2}=p^{2} c^{2}+m^{2} c^{4}$

onde $c$ é a velocidade da luz no vácuo, obtém-se a equação quântica correspondente (eq. de Klein-Gordon) substituindose, na equação acima, $E$ e $p$ pelos respectivos operadores:

$$
E \rightarrow i \hbar \frac{\partial}{\partial t} \quad e \quad \vec{p} \rightarrow-i \hbar \vec{\nabla}
$$

onde e $\vec{\nabla}=\frac{\partial}{\partial x} \hat{i}+\frac{\partial}{\partial y} \hat{j}+\frac{\partial}{\partial z} \hat{k} e\{\hat{i}, \hat{j}, \hat{k}\}$ é o conjunto de vetores unitários associados aos eixos cartesianos x, $y$ e $z$. Assim, a equação de Klein-Gordon é

$\left(\nabla^{2}-\frac{1}{c^{2}} \frac{\partial^{2}}{\partial t^{2}}\right) \psi=\frac{r^{2} c^{2}}{\hbar^{2}} \psi$

Quando $m=0$ esta equação se reduz à equação de d'Alembert, 
que descreve a propagação de uma onda eletromagnética clássica ou de um fóton sem massa.

No caso estático, com simetria esférica, $\psi$ só depende da distância $(r)$,

$$
\nabla^{2} \psi(r)=\frac{1}{r^{2}} \frac{\partial}{\partial r}\left(\frac{r^{2} \partial \psi}{\partial r}\right)=\frac{m^{2} c^{2}}{\hbar^{2}} \psi(r)
$$

Se a fonte pontual está na origem, para $r>0$, a solução (análoga a de uma carga eletrostática) é do tipo

$$
\psi(r)=\frac{\mathrm{g}}{r} e(-r / R)
$$

onde $R=\hbar /(m c)$. Esta quantidade tem dimensão de comprimento e representa o alcance da força. Vale notar que quando $m \rightarrow 0, R \rightarrow \infty$ e, portanto, forças de alcance infinito, como a eletromagnética e a gravitacional, são mediadas por quanta de massa nula. Dessa forma, para que $R$ seja da ordem de $10^{-13} \mathrm{~cm}$ parece ser necessário que o quantum do campo nuclear seja massivo $(m \approx 140 \mathrm{MeV})$.

\section{"Out of the fusion of relativity with quantum mechanics there has evolved a new view of the world, one in which matter has lost its central role. This role has been usurped by principles of symmetry, some of them hidden from view in the present state of the universe."}

\section{S. Weinberg ${ }^{48}$}

\section{A EQUAÇÃO DE DIRAC: SIMETRIAS E ANTI-PARTÍCULAS}

A equação de Schrödinger, eq. (1), é uma equação nãorelativística, pois envolve derivadas espaciais de segunda ordem, enquanto a derivada temporal é de primeira ordem. Entretanto, cabe notar que o próprio Schrödinger havia chegado a uma equação relativística para o elétron do átomo de hidrogênio, mas o espectro calculado com base nesta equação não estava de acordo com a experiência. Teoria e experimento só estavam de acordo, neste caso, no limite não-relativístico. Sabese hoje que o desacordo estava em não considerar o spin do elétron, sequer conhecido naquela época.

A equação relativística de Schrödinger foi redescoberta mais tarde por Klein e Gordon, eq. (5). Além do fato dela descrever partículas de spin zero - como o méson $\pi$, e não elétrons de spin $1 / 2$ - dela resulta ainda uma contradição conceitual com a interpretação probabilística da Mecânica Quântica, proposta por Max Born, ou seja: a equação de Klein-Gordon poderia levar a probabilidades negativas, o que é um absurdo. Como compatibilizar, então, a Mecânica Quântica e a Teoria da Relatividade?

Esta pergunta incomodou muito a Dirac naquele tempo ( 1926-28). Segundo seu próprio testemunho, ele estava tão impressionado com a beleza e a força do formalismo, baseado na equação de movimento de Heisenberg e a correspondente equação de Schrödinger ${ }^{49}$, que acreditava que a equação relativística para descrever o elétron movendo-se em um campo deveria ser de primeira ordem na derivada temporal:

$H \psi(\vec{x}, t)=i \hbar \frac{\partial \psi(\vec{x}, t)}{\partial t}$

Conseqüentemente, as derivadas espaciais também seriam de primeira ordem. A solução encontrada por Dirac foi a equação $0^{50}$ :

$\left\{i \hbar\left(\frac{\partial}{c \partial t}+\alpha_{1} \frac{\partial}{\partial x}+\alpha_{2} \frac{\partial}{\partial y}+\alpha_{3} \frac{\partial}{\partial z}\right)+\alpha_{4} m c\right\} \psi(\vec{x}, t)=0$ onde agora $\psi$ envolve quatro componentes em vez de uma só, como na eq. (7), e os coeficientes a são matrizes.

No caso de partículas livres, das quatro componentes de $\psi$, duas correspondem a partículas com energia relativística

$E=+\sqrt{p^{2} c^{2}+m^{2} c^{4}}$

e as outras duas correspondem a partículas com energia negativa, i.e.,

$E=-\sqrt{p^{2} c^{2}+m^{2} c^{4}}$

Ora, ao contrário dos estados ligados, uma partícula livre não pode ter energia negativa. Este foi o principal problema conceitual enfrentado por Dirac. Em primeiro lugar, a Mecânica Quântica não exclui a possibilidade de haver transições entre estados de energia positiva e negativa. Dirac compreendeu que estes estados de energia negativa não poderiam ser desconsiderados, mesmo porque se isto fosse feito haveria problemas com a estrutura matemática da teoria. O próximo passo teve a ver com uma profunda revisão do conceito de vácuo. Em suas próprias palavras:

"If we cannot exclude [the negative energy states], we must find a method of physical interpretation for them. One can get a reasonable interpretation by adopting a new picture of the vacuum. Previously, people have thought of the vacuum as a region of space that is completely empty, a region of space that does not contain anything at all. Now we must adopt a new picture. We may say that the vacuum is a region of space where we have the lowest possible energy." 49

Espaço e matéria não mais se excluem reciprocamente, como na grande escola materialista da antigüidade. Quanto a isto cabe uma pequena digressão. No século XVII, Descartes havia sugerido que não deveria existir diferença entre espaço e matéria, embora ele não tenha sido capaz de estabelecer uma teoria mecânica baseada nesta idéia. Foi Newton quem teve êxito em sua teoria mecanicista, cuja base contrariava diretamente a convicção de Descartes, à medida que admitia a existência de átomos movendo-se no espaço absoluto; o sensorium divino. Maxwell, em sua teoria eletromagnética, também admite que a matéria e o espaço são independentes, sendo este último o meio de propagação dos campos. Já Dirac, ao tentar conciliar a Mecânica Quântica e a Relatividade Especial — que fundamenta a simetria entre espaço e tempo — é levado a descobrir uma profunda relação entre matéria e espaço; relação esta que decorre das simetrias matemáticas (do espaço-tempo e internas) sob as quais sua equação se matém invariante. Esta importante contribuição de Dirac está na base do desenvolvimento da Teoria Quântica de Campos. É no âmbito do formalismo geral desta teoria, capaz de tratar processos de criação e aniquilação de partículas (o que não é possível na Mecânica Quântica de Schrödinger), que se define o vácuo e se descreve a dinâmica das interações entre partículas elementares, o que, por sua vez, obriga que se reveja o conceito de elementar, como será discutido na última seção deste artigo.

Inspirado na teoria da valência química, Dirac imagina que o vácuo seja o estado com todos os níveis de energia negativa ocupados pelos elétrons ${ }^{51,52}$ — chamado de mar de elétrons —, de modo análogo a como se preenchem as camadas fechadas dos átomos. Desta forma, de acordo com o princípio de exclusão de Pauli, um elétron de energia positiva não poderia nunca sofrer uma transição para estados de energia negativa. No entanto, um desses elétrons do mar poderia ser excitado para um estado de energia positiva, deixando no mar o que Dirac chamou de buraco. Cada buraco é interpretado como uma partícula de carga elétrica positiva e massa positiva. Por simetria, Dirac achou que este buraco deveria ter a mesma 
massa do elétron, embora com carga elétrica positiva. Entretanto, naquela época, a única partícula com carga elétrica positiva conhecida era o próton! Como explicar então a diferença de massa da ordem de 2000 vezes?

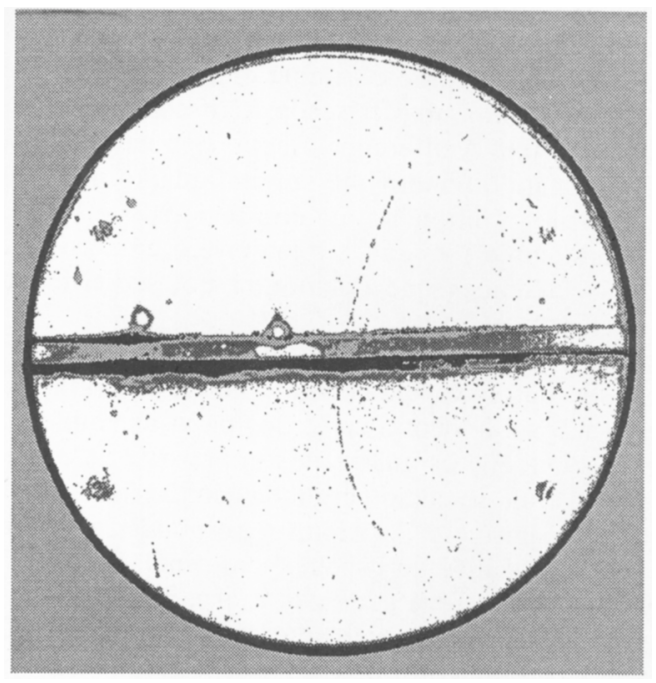

Figura 1. Fotografia do traço de ionização deixado por um pósitron em uma câmera de nuvem no experimento de Anderson ao atravessar uma placa de chumbo de $6 \mathrm{~mm}$. Extraída do livro de John Darius; Beyond Vision, Oxford Univ. Press; Oxford, 1984, que utilizou como fonte a foto do Science Museum de Londres.

Foi Weyl quem primeiro acreditou na existência de outra partícula com massa igual a do elétron, pelos motivos que o próprio Dirac relata e que valem a pena serem lembrados:

"He [Weyl] said boldly that the holes had to have the same mass as the electron. Now Weyl was a mathematician. He was not a physicist at all. He was just concerned with the mathematical consequences of an idea, working out what can be deduced from the various symmetries. And this mathematical approach led directly to the conclusion that the holes would have the same mass as the electron." 52

Pouco menos de um ano foi necessário para que esta previsão matemática — de certa forma ditada pelo ideal de simplicidade e de beleza de uma teoria - tivesse uma confirmação experimental. Foi Anderson quem descobriu o pósitron, ou o anti-elétron, com massa idêntica à do elétron e com carga elétrica de mesmo valor mas de sinal oposto ${ }^{53}$. A fotografia anterior (figura 1) mostra o traço deixado por um pósitron em uma câmara de bolha. Era assim detectada, pela primeira vez, uma anti-partícula em laboratório, que havia sido prevista pela teoria de Dirac.

We do not have any principle which says how many [different] quarks should exist. Therefore, even apart from any symmetry between quarks and leptons, we should not be surprised if in the future new hadrons are discovered which require additional quarks to account for them.

D.B. Lichtenberg ${ }^{54}$

\section{LÉPTONS E QUARKS}

Hoje conhecem-se mais de cem partículas. Em vez de detalhar os aspectos fenomenológicos deste imenso zoológico de partículas, é preferível apresentar agora as principais formas de classificação dessas partículas para o leitor não habituado com o jargão da Física de Partículas ${ }^{6,55}$. Inicialmente pensouse em classificá-las quanto a sua massa: bárions (do grego pesado), mésons e léptons (do grego leve). Todos os mésons são instáveis e têm spin inteiro. Todos os bárions têm spin semi-inteiro e também são instáveis, com exceção do próton. Do ponto de vista estatístico (que rege o comportamento coletivo de qualquer agregado de partículas), quando o spin é um múltiplo inteiro de $\hbar$, a partícula é chamada de bóson; aquelas cujo spin é um múltiplo semi-inteiro de $\hbar$ chamam-se férmions.

Outra classificação útil é quanto ao tipo de interação: aquelas partículas que sofrem interações fortes são chamadas hádrons (do grego adrós, que significa "forte") e as que não têm interação forte, i.e., participam somente das interações eletromagnéticas e fracas, chamam-se léptons (todos de spin 1/2).

Observando atentamente os seis léptons conhecidos hoje vêse que é possível grupá-los em três pares: o elétron $(e)$ e seu neutrino associado $\left(v_{\mathrm{e}}\right)$, o múon $(\mu)$ e seu neutrino $\left(v_{\mu}\right)$, o tau $(\tau)$ e seu neutrino $\left(v_{\tau}\right)$.

$$
\left(\begin{array}{l}
v_{e} \\
e^{-}
\end{array}\right) ;\left(\begin{array}{l}
v_{\mu} \\
\mu^{-}
\end{array}\right) ;\left(\begin{array}{l}
v_{\tau} \\
\tau^{-}
\end{array}\right)
$$

Este grupamento tem um sentido profundo relacionado com as interações fracas (unificação eletro-fraca) que não cabe aqui detalhar. Note, no entanto, que contrariamente aos léptons, existe uma centena de hádrons. Isto quer dizer que os léptons são mais fundamentais que os hádrons? A resposta é sim.

Nos anos 60, mostrou-se, pela primeira vez, que os hádrons poderiam ter constituintes mais elementares: os quarks. Quando este nome foi escolhido por Gell-Mann, em 1963, ele só tinha em mente o som da palavra, e não a grafia; algo como "kwork" ". Mais tarde ele encontrou a palavra quark no seguinte trecho do livro Finnegan's Wake de James Joyce ${ }^{57}$ :

"Three quarks for Muster Mark!

Sure he hasn't got much of a bark

And sure any he has it's all beside the bark."56

Vários modelos de constituintes para estas partículas antecederam o de Gell-Mann ${ }^{54}$ mas apenas este último será considerado aqui.

Com a descoberta das chamadas partículas estranhas ${ }^{58}$, como o méson $\mathrm{K}$, introduziu-se um novo número quântico aditivo chamado estranheza $(S)$. Tal número quântico seria conservado no processo de produção das partículas estranhas (processo forte) e violado nos seus decaimentos fracos em partículas não estranhas.

Considerando uma série de decaimentos, Gell-Mann e Nishijima generalizaram a Eq. (3), passando a escrever:

$\frac{Q}{e}=\frac{B+S}{2}+I_{z}$

onde $B$ é o chamado número bariônico. Para o nucleon, $B=1$ e $S=0$, e se reobtém a Eq. (3).

Gell-Mann verificou que vários hádrons poderiam ser classificados, a partir da combinação de três entidades fundamentais (u, d, s), segundo a estrutura algébrica do grupo denominado $S U(3)$. Matematicamente, este grupo de simetria é a extensão natural - motivada pelo aparecimento das partículas estranhas — da simetria $S U(2)$ que descreve a independência das interações fortes em relação ao isospin. As diversas representações do grupo (chamadas multipletos) podem ser obtidas a partir da sua representação fundamental. Essas entidades fundamentais têm spin semi-inteiro (1/2) e seus números quânticos adicionais são mostrados na tabela 3. A estas entidades (u, d, s), denominadas quarks, Gell-Mann passou a atribuir um significado especial, por estarem associadas à representação fundamental do grupo $S U(3)$, com a qual se constróem 
as demais. Ele as considerou como entidades elementares, mas mneumônicas; entidades puramente matemáticas que desempenhariam, de certa forma, um papel análogo aos triângulos de Platão. Mais tarde outros quarks foram postulados. Este é o caminho "estático" de se chegar ao conceito de quarks, i.e., o caminho profundamente ligado à espectroscopia dos hádrons, fortemente calcado em argumentos de simetria. - E como seria a dinâmica destes objetos?

Tabela 3. Números quânticos associados aos quarks u, d e s.

\begin{tabular}{cccccc}
\hline & $\mathrm{B}$ & $\mathrm{I}$ & $\mathrm{I}_{\mathrm{s}}$ & $\mathrm{S}$ & $\mathrm{Q} / \mathrm{e}$ \\
\hline $\mathrm{u}$ & $1 / 3$ & $1 / 2$ & $+1 / 2$ & 0 & $+2 / 3$ \\
$\mathrm{~d}$ & $1 / 3$ & $1 / 2$ & $-1 / 2$ & 0 & $-1 / 2$ \\
$\mathrm{~s}$ & $1 / 3$ & 0 & 0 & -1 & $-1 / 3$ \\
\hline
\end{tabular}

No modelo a quarks os bárions são formados de 3 quarks e os mésons de um quark e um antiquark. Como já mencionado, os quarks são objetos de spin $1 / 2 \mathrm{e}$, portanto, devem se comportar coletivamente do mesmo modo que os elétrons. No entanto, existe uma peculiaridade do modelo a quarks que é mais evidente, como será visto agora, no caso do bárion $\Delta^{++}$, que tem spin $3 / 2$ e é formado de três quarks do tipo u no estado fundamental. Sendo um férmion, a função de onda total do $\Delta^{++}$deveria ser anti-simétrica pela permuta de quaisquer dois quarks idênticos, mas tudo parecia indicar que ela fosse simétrica. Este paradoxo só foi resolvido em 1970, com a introdução de uma nova carga, de um novo número quântico chamado cor, que está na base da formulação da moderna teoria das interações fortes entre os quarks: a "Cromodinâmica Quântica". A solução para esse paradoxo consiste em supor que os três quarks u não são na verdade idênticos, mas distinguíveis através de um novo grau de liberdade chamado "cor" ao qual está associada uma simetria unitária exata. A conseqüência deste fato é que os mésons e bárions devem ser "descoloridos", i.e., ter carga total de cor nula. Existe hoje uma série de evidências experimentais comprovando a existência deste novo número quântico.

Como se chegou à evidência de que o próton é formado por partículas mais elementares — os partons - que mais tarde vão ser identificadas com os quarks e gluons?

Em 1968, foi feito um experimento onde o elétron $(e)$ é espalhado por um próton $(p)$ com grande transferência de energia e momentum e, do estado final, observam-se apenas a energia e o ângulo de espalhamento $(\theta)$ do elétron, ignorando-se a grande quantidade de outras partículas $(X)$ produzidas (figura 2). Esse é um processo que ficou conhecido na literatura como "espalhamento profundamente inelástico", usualmente denotado por $e p \rightarrow e X$.

$\mathrm{Da}$ análise dos dados desse experimento pode-se concluir que a carga elétrica do próton é localizada em pequenos centros

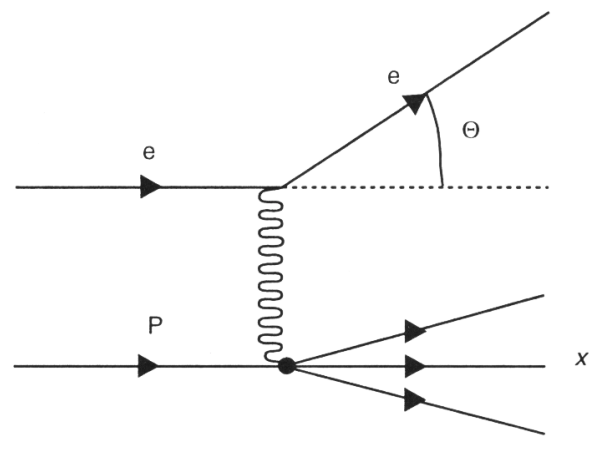

Figura 2. Esquema para o Espalhamento Profundamente Inelástico, do elétron (e) pelo próton (p), visto no laboratório onde o próton está em repouso. espalhadores de spin $1 / 2$ e sem estrutura, batizados de partons por Feynman ${ }^{59}$. Este é o mesmo tipo de inferência que, em última análise, fez Rutherford no seu experimento com partículas $\alpha$, ao concluir que os átomos deveriam possuir um núcleo de dimensões 10 mil vezes menor que o raio característico dos átomos. No caso do hidrogênio, este núcleo seria somente o próton. Portanto, cerca de 60 anos foram necessários entre a descoberta do próton como partícula elementar e a descoberta de sua sub-estrutura; ambas baseadas em resultados de experimentos de alvo fixo. A diferença crucial está na escala de energia disponível para o feixe. Hoje em dia, quanto mais se deseja explorar a estrutura íntima da matéria maior deve ser a energia do feixe usado como "sonda"60, e maior é o número de físicos, engenheiros e técnicos que colaboram nos experimentos dos grandes aceleradores.

$\mathrm{O}$ resultado do espalhamento inelástico $e p \rightarrow e X$, combinado com dados de outros espalhamentos inelásticos (induzidos por neutrinos) vai levar à identificação dos partons com os quarks. Mas viu-se acima que os quarks possuem carga de cor, além da carga elétrica. Pode-se então perguntar: quais são os mediadores dessa interação sensível à cor? Para se responder a esta pergunta deve-se voltar à análise do espalhamento inelástico.

Os partons foram revelados nesse espalhamento ep através de fótons trocados entre o elétron e o próton ${ }^{61}$ (figura 2). Portanto, todos esses constituintes são eletricamente carregados e, da soma dos momentos lineares destes partons em um particular sistema de referência, dever-se-ía encontrar o momento linear total do próton, neste mesmo sistema. Acontece que tal cálculo dá como resultado que os partons carregam apenas a metade do momento linear total do próton! Logo, onde está a outra metade?

Sendo a interação fundamental de natureza eletromagnética, uma resposta plausível viria da existência de partons neutros (sem carga elétrica), os quais não seriam naturalmente "vistos" pelos fótons. São estes partons que serão mais tarde identificados com os gluons, termo que vem da palavra inglesa glue, que significa cola. Os gluons, de certa, forma se assemelham aos fótons e são os responsáveis pela mediação da interação forte entre os quarks, ou seja, pela coesão dos quarks dentro dos mésons e bárions. Eles "vêem" a carga de cor; são partículas de spin 1 sem massa mas, ao contrário dos fótons, que não possuem carga elétrica, possuem carga de cor.

Outros três bósons "vetoriais" (spin 1) foram descobertos mais $\operatorname{tarde}^{62,63}$. São eles os bósons $\mathbf{Z}$ e $\mathbf{W}$, observados nos seguintes estados de carga elétrica: $\mathbf{Z}^{0}, \mathbf{W}^{+}$e $\mathbf{W}^{-}$. Juntamente com o fóton, são os mediadores das interações eletro-fracas entre quarks e léptons. Dito de outra forma, este são os quanta de uma teoria que unifica as interações eletromagnéticas e fracas.

Pode-se resumir, finalmente, o quadro teórico atual dos constituintes últimos da matéria. Existem doze partículas sem estrutura (os "a tomos"): seis quarks e seis léptons. Os mediadores das interações forte e eletro-fraca são, respectivamente, oito tipos de glúons, o fóton e mais os bósons pesados $\mathbf{Z}$ e $\mathbf{W}$. Convencionou-se chamar de "Modelo Standard" o modelo atualmente aceito por boa parte da comunidade de físicos de partículas para a descrição das interações entre quarks e léptons. As partículas elementares deste modelo são apresentadas na seguinte tabela (Figura 3).

O último quark detectado, o quark Top, só foi observado no início de 1995, por dois grandes experimentos no FERMILAB $^{64,65}$, em um dos quais participa um grupo brasileiro (LAFEX/CBPF). O leitor interessado pode consultar o artigo de divulgação sobre a descoberta do top publicado na revista Ciência Hoje $e^{66}$.

Uma pergunta fundamental que se deve por é a seguinte: com a descoberta destas partículas, até agora desejadas pela teoria, ter-se-ia exaurido todo o esquema de partículas? Aparentemente, hoje muitos responderiam que sim, mas esta resposta não é correta $^{25}$. E mesmo que fosse, como gosta de salientar Santoro, "só 


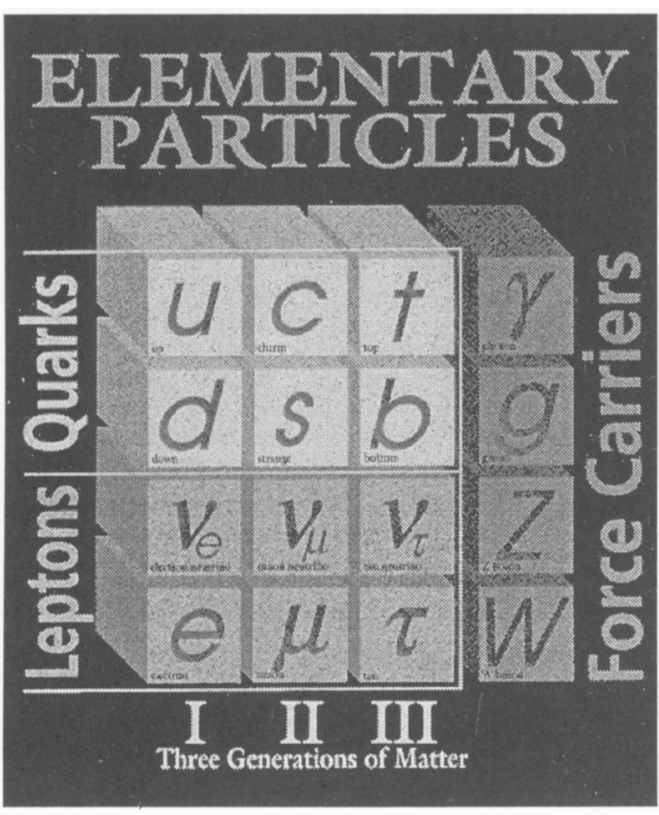

Figura 3. Tabela das Partículas Elementares de hoje segundo material divulgado pelo Fermilab, por ocasião da descoberta do quark top. Original gentilmente cedido pela Colaboração D0 do Fermilab.

se teria aprendido o alfabeto e fica toda a literatura a ser escrita". Mas, na verdade, a lição que se tira da experiência é que todas as vezes que se acredita ter chegado ao "fundo do poço", surgem novas e grande surpresas. Portanto, em que sentido são os quarks e léptons elementares?

$\mathrm{Na}$ filosofia grega, entidades elementares eram definidas como aquelas que não poderiam ser divididas posteriormente em constituintes ainda menores (átomo $=$ indivisível). Já a Física Clássica (e, em particular, a Mecânica Celeste) tornou muito natural que se considerasse como elementar qualquer coisa que pareça puntiforme na escala daquilo que se está observando. Por isso, na passagem da Mecânica Clássica ao campo da Física de Partículas, se é tentatado a adotar a seguinte definição de elementar: qualquer coisa da qual não se veja a estrutura é elementar. Com a ressalva de que esta pode se revelar uma conclusão provisória, ou seja, aquilo que não é visível a olho nú poderá ser visto ao microscópio, ou mesmo ao microscópio eletrônico, ou mesmo a um aparelho de pesquisa muito mais sofisticado. Este é o caso do átomo da Química.

Uma característica importante das famílias de quarks e de lépton, mostradas na figura 3, é que todos os seus integrantes se comportam como elementares, no sentido de não apresentarem nenhuma estrutura, pelo menos até as dimensões mais extremas exploradas até o presente, ou seja, cerca de $10^{-18}$ metros. No entanto, um quark pode decair em outro mais léptons, ou um lépton pode decair em outros. No caso dos léptons, por exemplo, é digno de nota que há uma significativa diferença de massa entre estas partículas (cuja origem não se sabe), e duas das três, embora elementares, são instáveis (o $\mu$ e o $\tau$ ), sendo que o tau se desintegra expontaneamente em partículas que, elas mesmas, apresentam uma estrutura!! Portanto, o critério de estabilidade não serve para definir a elementariedade das partículas. Pode parecer paradoxal que uma partícula sem estrutura possa gerar outras com estrutura, mas isto faz parte de uma espécie de democracia entre as partículas, permitida, em parte, pela intrínseca relação entre massa e energia. Logo, se as partículas elementares podem ser identificadas como os átomos, lato sensu, da Física Moderna, perde-se, com relação à Química Clássica, a convicção de que a indivisibilidade está diretamente relacionada à indestrutibilidade e o caráter elementar passa a depender dos limites de resolução experimental. Apesar destas diferenças, persiste, como elemento dominante nas pesquisas em Física de Partículas, o paradigma de átomo, com as ressalvas feitas acima.

\section{AGRADECIMENTOS}

Agradecemos aos organizadores do Encontro entitulado $E d u$ cação e Desenvolvimento Científico e Tecnológico, realizado há alguns anos em Nova Friburgo, Rio de Janeiro, pelo convite à reflexão sobre como falar de átomos e partículas elementares a licenciandos e a alunos do segundo grau, que acabou motivando-nos a escrever este texto. Agradecemos também aos amigos Gilvan Alves, Nádia Caruso, Roberto Moreira Xavier, Bruto Pimentel e Alberto Santoro por proveitosas discussões. Este trabalho contou parcialmente com o apoio do CNPq.

\section{REFERÊNCIAS E NOTAS}

1. Sambursky, S.; Physical World of the Greeks; Princeton Univ. Press; Princeton; New Jersey, 1987.

2. Caruso, F.; "Dividindo o Indivisível", In Do átomo Grego à Física das Interações Fundamentais; Caruso, F.; Santoro, A., Eds.; AIAFEX; Rio de Janeiro, 1994; pp. 49-59.

3. Heisenberg, W.; Física e Filosofia; Ed. Univ. de Brasília; Brasília, 1981.

4. Plato, Timaeus, 54, In The Collected Dialogs, Hamilton, E.; Cairns, H., Eds.; Princeton Univ. Press; Princeton, fourteenth printing, 1989; p. 1180.

5. Kirk, G. S.; Raven J. E.; Schofield, M.; Os Filósofos PréSocráticos, 4a. edição, Fundação Calouste Gulbenkian; Lisboa, 1994.

6. Bassalo, J. M. F.; "Partículas Elementares: do átomo grego à supercorda", In op. cit., Caruso, F.; Santoro, A., Eds.; pp. 87-165.

7. Gell-Mann, M.; Phys. Lett. 1964, 8, 214; Zweig, G. CERN Report TH. 401 (1964) não publicado; $C f$. também GellMann, M.; Ne'eman, Y.; The Eightfold Way; Frontiers in Physics; W. A. Benjamin, 1964.

8. Bachelard, G.; O Novo Espírito Científico; Tempo Brasileiro; Rio de Janeiro, 1968.

9. Galileo, Il Saggiatore, $6^{\circ}$; Istituto Editoriale Italiano; Milano; s/d; pp. 44-5.

10. Newton, I.; Opticks; Dover Edition; New York, 1952, based on the fourth edition London, 1730.

11. Planck, M.; Annalen der Physik 1901, 4, 553.

12. Einstein, A.; Annalen der Physik 1905, 17, 144.

13. Compton, A.; Physical Review 1923, 21, 483.

14. Bohr, N.; Os principais artigos sobre o modelo atômico de Bohr encontram-se, traduzidos em Português, In Sobre a Constituição dos átomos e Moléculas; 2a. edição, Fundação Calouste Gulbenkian; Lisboa, 1979.

15. De Broglie, L.; Tese de Doutorado. Cf. também seus livros: La Physique Nouvelle et les Quanta; Flammarion; Paris, 1937; Jalons pour une Nouvelle Microphysique; Gauthier-Villars; Paris, 1978.

16. Independentemente, em 1925, Heisenberg propõe a sua mecânica das matrizes que, como mostrará um pouco mais tarde o próprio Schrödinger, é equivalente à sua mecânica ondulatória. São duas visões equivalentes da nova Mecânica Quântica.

17. Schrödinger, E.; Annalen der Physik 1926, 79. Tradução para o inglês In Collected Papers on Wave Mechanics; Chelsea Publ.; New York, Third (augmented) edition, 1982.

18. Leite Lopes, J.; A Estrutura Quântica da Matéria: Do átomo Pré-Socrático às Partículas Elementares; Ed. UFRJ/Erca; Rio de Janeiro, 1992.

19. Gibert, A.; Origens Históricas da Física Moderna; Fundação Calouste Gulbenkian; Lisboa, 1982. 
20. Pergunta feita por Berlikov em uma reunião dos membros da Sociedade Russa de Química, apud Posin, D. Q.; Mendeleyev: The Story of a Great Scientist; Whittlesey House; New York, 1948; 175-6.

21. Exceto os compostos não estequiométricos.

22. Ibid.; p. 185. Cf. ainda Mendeleyev, D.; The Principles of Chemistry; 3rd. English ed., Longmans, Green \& Co., New York, 1905.

23. Taton, R.; "L'essor de la Chimie", In La Science Contemporaine; Presses Univ. de France, Paris, 1961; Tome III, Chap. VII, pp. 299-340.

24. Einstein, A.; Investigations on the Theory of Brownian Movement; Dover; N. Y., 1956.

25. Begalli, M.; Caruso, F.; Predazzi, E.; "O Desenvolvimento da Física de Partículas", In op. cit.; Caruso, F.; Santoro, A., Eds.; pp. 71-85.

26. De Carvalho, R.; História do átomo; Atlântida; Coimbra, 1955.

27. Thomson, G. P.; J. J. Thomson and the Cavendish Laboratory in his Day; Thomas Nelson; London, 1964.

28. Thomson, J. J.; Philosophical Magazine. 1987, 44, series $5,293$.

29. Millikan, R. A.; Physical Review. 1911, 32, p. 349.

30. Partículas de carga positiva emitidas por certas substâncias radioativas. Hoje sabe-se que é o núcleo do átomo de $\mathrm{He}$.

31. Rutherford, E.; Philosophical Magazine. 1911, 21, 669.

32. Large Electron Positron Collider.

33. European Laboratory for Particle Physics.

34. Fermi National Accelerator Laboratory.

35. Large Hadron Collider.

36. Apud Pais, A.; Inward Bound of Matter and Forces in the Physical World; Clarendon Press; Oxford, 1988. Para detalhes veja Ref. [38].

37. Quantum do campo eletromagnético introduzido para explicar efeitos como o fotoelétrico e o Compton.

38. Chadwick, J.; Proc. Roy. Soc. London. 1932, A136, 692.

39. Emissão de elétrons por um núcleo.

40. Devido à semelhança entre a álgebra dos operadores de spin na Mecânica Quântica e os operadores de isospin, que é a álgebra do grupo $\mathrm{SU}(2)$.

41. Fermi, E.; Particelle Elementari; Einaudi; Torino, 1952; p. 17.

42. Yang, C. N.; Elementary Particles: a Short History of some Discoveries in Atomic Physics; Princeton Univ. Press; New Jersey, 1961.
43. Pais, A. op. cit.

44. Segrè, E.; Dos Raios X aos Quarks; Ed. Univ. de Brasília; Brasília, s/d.

45. $C f$. também alguns capítulos dos 3 tomos de Bassalo, J. M. F.; Crônicas da Física; Ed. Univ. Federal do Pará; Belém, 1987-92.

46. Lattes, C. M. G.; Occhialini, G. P. S.; Powell, C. F.; Nature. 1947, 160, 453

47. Marques, A., Ed.; Cesar Lattes 70 Anos: a Nova Física Brasileira; Centro Brasileiro de Pesquisas Físicas; Rio de Janeiro, 1994.

48. Weinberg, S.; Dreams of a Final Theory; Vintage Books; New York, 1993; p. 3.

49. Dirac, P. A. M.; In Directions in Physics, Hora, H.; Shepanski, J. R., Eds.; John Wiley; New York, 1978; pp. 2-20.

50. Dirac, P. A. M.; Proc. Roy. Soc. 1928, A117, 610.

51. Dirac, P. A. M.; Proc. Roy. Soc. 1931, A133, 60.

52. Dirac, P. A. M.; The Development of Quantum Theory; Gordon \& Breach; New York, 1971.

53. Anderson, C. D.; Physical Review 1933, 43, 491.

54. Lichtenberg, D. B.; Unitary Symmetry and Elementary Particles; Academic Press; New York, 1978.

55. Shellard, R.; "A Natureza da Natureza", in op. cit., Caruso, F.; Santoro, A., Eds.; pp. 167-197.

56. Gell-Mann, M.; Le Quark et le Jaguar: voyage au coeur du simple et du complexe; Albin Michel; Paris, 1995.

57. Neste contexto, a palavra quark é uma forma arcaica para croak (que entre outras coisas significa coaxo), e obviamente foi escolhida para rimar com Mark e bark. A justificativa para a pronuncia "kwork" pode ser encontrada $\mathrm{em}^{56}$.

58. Estranhas pois elas tinham uma vida média muito superior ao esperado via interações fracas.

59. Feynman, R. P.; Phys. Rev. Lett. 1969, 23, 1415.

60. Elétrons no espalhamento profundamente inelástico e partículas a no experimento de Rutherford.

61. Breidenbach, A.; et. al.; Phys. Rev. Lett. 1969, 23, 935.

62. UA1 Collaboration; Phys. Lett. 1983, 122B, 103.

63. UA2 Collaboration; Phys. Lett. 1983, 122B, 476.

64. D0 Collaboration, Abachi, S.; et. al.; "Observation of the Top Quark", Phys. Rev. Lett. 1995, 74, 2632.

65. CDF Collaboration, Abe, F.; et. al.; Phys. Rev. Lett. 1995, 74, 2626

66. Alves, G. A.; Santoro, A.; Souza, M. H. G.; Ciência Hoje. 1995, 19, 113, 34-44. 